\title{
CALCULATION METHOD TO DETERMINE THE GROUP COMPOSITION OF VACUUM DISTILLATE WITH HIGH CONTENT OF SATURATED HYDROCARBONS
}

\author{
Galina Nazarova ${ }^{1, *}$, Elena Ivashkina $^{1}$, Tatyana Shafran $^{1}$, and Nataliya Belinskaya ${ }^{1}$ \\ ${ }^{1}$ Tomsk Polytechnic University, Lenin av. 30, Tomsk, 634050, Russia
}

\begin{abstract}
Calculation method to determine the group composition of the heavy fraction of vacuum distillate with high content of saturated hydrocarbons, obtained by vacuum distillation of the residue from the West Siberian oil with subsequent hydrotreating, are given in this research. The method is built on the basis of calculation the physico-chemical characteristics and the group composition of vacuum distillate according to the fractional composition and density considering with high content of saturated hydrocarbons in the fraction. Calculation method allows to determine the content of paraffinic, naphthenic, aromatic hydrocarbons and the resins in vacuum distillate with high accuracy and can be used in refineries for rapid determination of the group composition of vacuum distillate.
\end{abstract}

\section{Introduction}

Heavy petroleum fractions are the multicomponent mixture with a predominance of high molecular weight hydrocarbons, resins and asphaltenes, carbenes, carboids, organic compounds with heavy metals $(\mathrm{V}, \mathrm{Ni}, \mathrm{Fe}, \mathrm{Mn}$, etc.) and heteroatoms $(\mathrm{S}, \mathrm{O}, \mathrm{N}, \mathrm{F})[1,2]$. Hydrocarbon components of heavy petroleum fractions are divided into the three main types: paraffinic, aromatic and naphthenic structures.

A group composition of petroleum fractions during an oil refining processes is the most important factor influencing in the yield and composition of products, and an efficiency of the catalysts. Information about the group composition of petroleum fractions is required during a design of industrial installations, optimization of oil refining processes, prediction of the composition, yield and quality of products from industrial units and the development and improvement of highly efficient catalyst compositions, evaluating the deactivationetc.

In the condition of intensive development of advanced petroleum refining processes and catalysts, there is much tension around the issue of optimization of industrial unit by experimental ways and mathematical modeling [3-6]. Mathematical models should be based on the physical-chemical patterns and taken into account the constantly changing group composition of heavy petroleum fractions to adequately describing the processes. It is known that the regular analysis of the fractional composition of heavy fractions do not reliably reflect the group composition. 
There are different calculation methods to determine the physico-chemical characteristics, structural-group and group composition of petroleum fractions [7-10]. Such methods are based, for the most part, on the correlation dependencies depending on the boiling point and molecular weight of the fractions.

N-d-M method was proposed in 1951 for the calculation of structural-group composition of petroleum fractions according to the refractive index, density and molecular weight. The method allows to determine the carbon content in naphthenic, aromatic and paraffinic structures and average number of naphthenic and aromatic rings [11]. TOTAL correlation allows to determine the weight content of aromatic hydrocarbons in fraction on the basis of the fractional composition, density, and aniline point [12].

Calculation method to determine the group composition of petroleum fractions based on the viscosity gravity constant and refractivity intercept was proposed in 1980. Laboratory results on the fractional composition, density and kinematic viscosity are required as input data for the calculation of the group composition according to the API method. It allows calculating the group composition for light and heavy petroleum fractions with molecular weight in the range of 70-200 and 200-600 respectively [13].

Calculation method to determination of the group composition of petroleum fractions on the basis of laboratory results on the fractional composition, density, refractivity intercept and ratio $\mathrm{C} / \mathrm{H}$ was proposed in 1986 [14]. In [15] authors offered to calculate the group composition of petroleum fractions on the basis of density and refractive index. In [16], a new method was proposed for correlations elaboration based on the use of pure hydrocarbons specific data using normal boiling point, density, refractive index and carbon to hydrogen weight ratio.

According to the high content of saturated hydrocarbons in vacuum distillate from West Siberian oil, the molecular weight and refractive index should be calculated considering with characteristic factors of vacuum distillate.

Therefore, the aim of the research is the development of calculation method to determine the group composition of vacuum distillate based on the data of the fractional composition and density considering with high content of saturated hydrocarbons.

\section{Research methods}

Fractional composition and density of vacuum distillate was determined according to ASTM D 2887 and GOST 3900.

Liquid adsorption chromatographic separation on silica gel ASA with a grain size of 0.2 - $0.3 \mathrm{~mm}$ was performed according to VNII NP algorithm with the aim to determine the group composition of vacuum distillate. Structural-group composition of paraffinnaphthenic fractions was determined by the $\mathrm{n}$-d-m-method, for aromatic hydrocarbon fraction by the Hazelvude-method using refractometer IRF-22.

The research in the determination of molecular weight vacuum distillate was performed by device CRYETTEWR, determining the freezing point of the samples (accuracy of the cryoscope temperature measurement is \pm (2-5) millidegree Celsius).

\section{Results and discussion}

\subsection{Development of calculation method for determining the group composition of heavy fraction of vacuum distillate}

Initial data for calculation of the group composition of vacuum distillate with high content of saturated hydrocarbons are fractional composition and density. According to 
experimental data the density of vacuum distillate is changed in the range of $0.8990-$ $0.9055 \mathrm{~g} / \mathrm{cm} 3$, Boiling temperature is changed in the range of 282-306 for initial boiling point, of 360-373 for $10 \%$ by volume, of $435-445$ for $50 \%$ by volume, and of $515-540$ for $90 \%$ by volume.

Laboratory results for determining the group and structural-group composition and molecular weight of vacuum distillate from West Siberian oil is presented in Table 1.

Table 1. The group and structural-group composition and molecular weight of vacuum distillate

\begin{tabular}{|c|c|c|c|}
\hline \multicolumn{1}{|c|}{ Characteristics } & \multicolumn{3}{|c|}{ Values } \\
\hline Molecular weight, g/mol & \multicolumn{3}{|c|}{382.43} \\
\hline \multirow{2}{*}{ Group composition, wt.\% } & Saturated hydrocarbons & Aromatic hydrocarbons & Resins \\
\cline { 2 - 4 } & 61.20 & 35.57 & 3.23 \\
\hline Content of carbon in: & n-d-m-method & Hazelvude-method & - \\
\hline - paraffinic structures & 66.14 & 16.76 & - \\
\hline - naphthenic structures & 31.27 & 55.73 & - \\
\hline - aromatic structures & 2.59 & 27.52 & - \\
\hline Number of aromatic rings & 0.14 & 1.40 & - \\
\hline Number of naphthenic rings & 2.05 & 3.90 & - \\
\hline Total number of rings & 2.19 & 5.30 & - \\
\hline
\end{tabular}

According to Table 1, vacuum distillate are characterized by high content of saturated hydrocarbons (61.2 wt. \%), molecular weight is $382.43 \mathrm{~g} / \mathrm{mol}$. The content of carbon in paraffinic and naphthenic structures is $66.14 \%$ and $31.27 \%$ respectively, the average number of rings is $2.05 \%$ in paraffin-naphthenic fraction

According to the analysis of aromatic concentrates by the Hazelvude-method the aromatic structure is presented by hybrid structures. In aromatic fractions isolated from vacuum distillate the average number of naphthenic rings (3.9 units) is more than the number of aromatic rings (1.4 units), the total content of rings is 5.3 units. Carbon content in paraffinic fragments of aromatic concentrate indicates the presence of alkyl substituted of aromatic hydrocarbons and naphthenes; the content of paraffins fragments $-16.76 \%$.

Method API [13] is accepted as the basis for the calculations. The following are the main stages of the calculation to determine the group composition of vacuum distillate according to the developed method.

1. Definition of average volume boiling point $\left(\mathrm{T}_{\mathrm{vol}},{ }^{\circ} \mathrm{F}\right)$ and molecular boiling point $\left(\mathrm{T}_{\mathrm{m}}\right.$, ${ }^{\circ} \mathrm{F}$ ) according to the the results of fractional composition of vacuum distillate [10]:

$$
\begin{gathered}
T_{\mathrm{vol}}=\left(T_{10 \%}+T_{50 \%}+T_{90 \%}\right) / 3 \\
\left.T_{\mathrm{m}}=T_{\mathrm{vol}}-\left[\left(T_{90 \%}-T_{10 \%}\right) /\left(170+0.075 \cdot T_{\mathrm{vol}}\right)+1.5\right)\right]+2
\end{gathered}
$$

here $\mathrm{T}_{10 \%} ; \mathrm{T}_{50 \%} ; \mathrm{T}_{90 \%},{ }^{\circ} \mathrm{C}$ - boiling point of $10 \%, 50 \%$ and $90 \%$ volume.

3. Calculation of characteristic factor by the UOP method $\left(\mathrm{K}_{\mathrm{UOP}}\right)$ :

$$
K_{\mathrm{UOP}}=\left[\left(T_{\mathrm{vol}}+460\right) / p\right]^{1 / 3}
$$

here $\mathrm{p}$ - density of vacuum distillate at $15^{\circ} \mathrm{C}, \mathrm{g} / \mathrm{cm}^{3}$.

4. Calculation of molecular weight (MW) by refined Voinov equation depending on the characteristic factor and molecular boiling point of fraction $\left({ }^{\circ} \mathrm{C}\right)$ [17]:

$$
M W=\left(7 \cdot K_{\mathrm{UOP}}-21.5\right)+\left(0.76-0.04 \cdot K_{\mathrm{UOP}}\right) \cdot T_{\mathrm{m}}+\left(0.0003 \cdot K_{\mathrm{UOP}}-0.00245\right) \cdot T_{\mathrm{m}}{ }^{2}
$$

5. Defined the refractive index at $20^{\circ} \mathrm{C}\left(\mathrm{n}^{20}\right)$ according to R. Hersch and M. Fenske equation connecting the molecular weight and molecular boiling point of fraction $\left({ }^{\circ} \mathrm{C}\right)$ : 


$$
n^{20}=2.1500-10^{(\lg M W-1.9939436-0.0019764 \cdot T \mathrm{~m})}
$$

6. Calculation of refractivity intercept (Ri) depending on refractive index and density and kinematic viscosity at $100^{\circ} \mathrm{C}\left(v_{100}, \mathrm{St}\right)$ from the experimental dependence:

$$
\begin{gathered}
R i=n^{20}-p / 2 \\
v_{100}=0.1488 \cdot \exp ^{0.0087 \cdot T_{\mathrm{vol}}}
\end{gathered}
$$

8. Determination of viscosity gravity constant (VGC) depending on the density and kinematic viscosity of fraction:

$$
V G C=\left[\left(p-0.24-0.022 \cdot \lg \left(v_{100}-35.5\right)\right] / 0.755\right.
$$

$\mathrm{v}_{100}$ - kinematic viscosity fraction at $100^{\circ} \mathrm{C}$, SSU.

9. Compilation of the three equations system for calculation of the group composition of of the vacuum distillate from the West Siberian oil is the final stage. The first equation is the molar balance of the group composition of vacuum distillate, the second and third equations are additive law for refractivity intercept and viscosity gravity constant.

$$
\left\{\begin{array}{l}
x_{p}+x_{N}+x_{A+R}=1 \\
1.0482 \cdot x_{p}+1.0359 \cdot x_{N}+1.0893 \cdot x_{A+R}=R i \\
0.7406 \cdot x_{p}+0.9289 \cdot x_{N}+0.9505 \cdot x_{A+R}=V G C
\end{array}\right.
$$

Here $x_{\mathrm{P}}, x_{\mathrm{N}}, x_{\mathrm{A}+\mathrm{R}}$ are the molar concentration of paraffinic, naphthenic and aromatic hydrocarbons with resins; $1.0822 ; 1.0359 ; 1.0893$ and $0.7406,0.9289,0.9505$ are the average refractivity intercept and viscosity gravity constant for paraffinic, naphthenic and aromatic hydrocarbons respectively.

Equation system is solved by Cramer method relatively $x_{\mathrm{P}}, x_{\mathrm{N}}$ and $x_{\mathrm{A}+\mathrm{R}}$. and the expressions for the calculation of the molar concentration of the hydrocarbon groups is obtained:

$$
\left\{\begin{array}{l}
x_{p}=2.6386+2.09302 \cdot R i-5.1744 \cdot V G C, \\
x_{N}=18.3721-20.3391 \cdot R i-3.9826 \cdot V G C, \\
x_{A+R}=-20.009690+18.2461 \cdot R i-1.1919 \cdot V G C .
\end{array}\right.
$$

According to experimental data, content of aromatic hydrocarbons is $90.25 \%$ from the total content of aromatic hydrocarbons with resins.

\subsection{Adequacy of calculation of the group composition of vacuum distillate with high content of saturated hydrocarbons}

Adequacy evaluation of the calculation method is performed by comparison between calculated and experimental data of the group composition of vacuum distillate (wt.\%) obtained in the laboratory on the device "GRADIENT-M". The content of resins, saturated and aromatic hydrocarbons in vacuum distillate depending on the average volume boiling point are presented in Fig. 1-3.

According to Fig. 1-3, the content of saturated hydrocarbons decreases and content of aromatic hydrocarbons and resins rises with increasing the average volume boiling point of vacuum distillate. Error between calculation and experimental data by the group composition in vacuum distillate is not more than $5.0 \mathrm{wt} . \%$. 


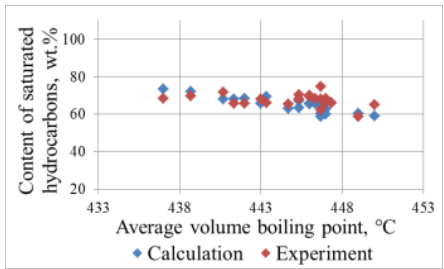

Fig. 1. The content of saturated hydrocarbons depending on the average volume boiling point.

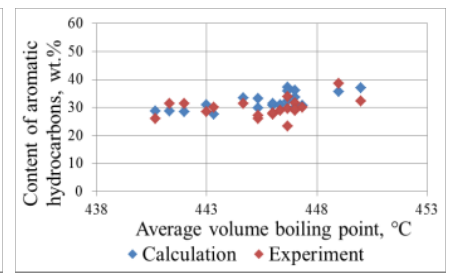

Fig. 2. The content of aromatic hydrocarbons depending on the average volume boiling point.

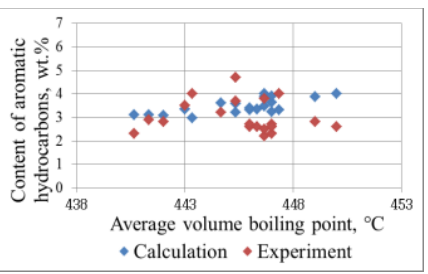

Fig. 3. The content of resins depending on the average volume boiling point.

\section{Conclusion}

The presented method allows to calculate with high accuracy (calculation error is not more than 5\%) the group composition of vacuum distillate with high content of saturated hydrocarbons (280-575 $\mathrm{S}$ fraction) on the basis of the fractional composition and density. The developed method takes into account the high content of saturated hydrocarbons and allows to calculate the content of saturated (paraffinic and naphthenic hydrocarbons), aromatic hydrocarbons and resins in vacuum distillate. Calculation method can be used in oil refineries for rapid determination of the group composition of vacuum distillate with high content of saturated hydrocarbons and in the complex with mathematical methods to improve the operating efficiency of industrial units of advanced petroleum processes and catalysts. Program realization of calculation methods is made using Delphi 7.0 software.

\section{References}

1. C. A. Hughey, R. P. Rodgers, A. G. Marshall, Anal. Chem. 74, 4145-4149 (2002)

2. N. Aske, Harald Kallevik, J. Sjoblom 15, 1304-1312 (2001)

3. V. A. Chuzlov, K. V. Molotov, Petroleum and Coal. 58(1), 47-55. (2016)

4. V. A. Chuzlov, E. D.Ivanchina, N. V. Chekantsev, K. V. Molotov, Procedia Engineering. 113, 131-137 (2015)

5. N. S. Belinskaya, E. D. Ivanchina, E. N. Ivashkina, V. A. Chuzlov, S. A. Faleev Procedia Engineering. 113, 68-72 (2015)

6. N.S. Belinskaya, E.V. Frantsina, E.D. Ivanchina, N.V. Popova, I.V., Zyryanova, E.V. Averyanova, IOP Conf. Series: Earth and Environmental Science 43, 1-6, (2016)

7. A. I. Levashova, N. V. Usheva, O. E. Moizes, I. Fedjaeva, Proceedings: KORUS 2004. 2, 63-64 (2010)

8. T. A. Albahri, Fluid Phase Equilibria, 315, 113-125 (2012)

9. M. R. Riazi, T. E. Daubert, Ind. Eng. Chem. Res. 26, 755-759 (1987)

10. L. P. Guilyazetdinov, Ind. Eng. Chem. Res. 34, 1352-1363 (1995)

11. R. Sadeghbeigi,Elsevier Inc. 361 (2012)

12. ASTM, Standard Test Method for Calculation of Carbon Distribution and Structural Group Analysis of Petroleum Oils by the n-d-M Method, ASTM Standart D 3238-5, ASTM, West Conshohocken (1985)

13. H.Dhulesia, Oil Gas J. 84, 51-54 (1986)

14. M. R. Riazi, T. E. Daubert, Ind. Eng. Chem. Process Des. Dev. 19, 289-294 (1980)

15. M. R. Riazi, T. E. Daubert, Ind. Eng. Chem. Process Des. Dev. 25, 1109-1115 (1986)

16. C. A. Nwadinigwe, K. A. Okoroji, Fuel 69, 340-343 (1990)

17. D. El-Hadi, M. Bezzina, Fuel 84, 611-617 (2005)

18. Yu.G. Kirsanov, Ural. University - Ekaterinburg, 136 (2014) 